\title{
Helen Salisbury: Do we need integration?
}

\author{
Helen Salisbury GP \\ Oxford
}

I recently went to a city-wide integration workshop, involving about 200 people from the new primary care networks. I was hoping to learn about local progress towards an integrated care system, as foretold in the NHS Long Term Plan, ${ }^{1}$ but I was disappointed. There seemed to be no big plan. There wasn't even a small plan, unless our leaders were keeping it to themselves.

Instead, we were seated in multi-professional groups and were asked to talk about our vision for integrated care and what we'd do to bring it about. It wasn't even clear what we were aiming to integrate: primary and secondary care? Healthcare and social care? Mental health and physical health? With its connotations of streamlining and efficiency, integration is an attractive concept. But, without clear parameters, it's just a hazy idea, certainly beyond the influence of jobbing GPs like us.

Theoretically, integrating social care and healthcare should be a winner, with hopes that joined-up provision will return patients home speedily after admission or even keep them out of hospital altogether, thus saving money. However, one large pilot study found that integrated care resulted in higher rather than lower costs per patient, possibly because thorough assessments revealed so much unmet need. ${ }^{2}$

It's clear that something needs to be done. Local authority budgets have been slashed, leaving social care in crisis. ${ }^{3}$ What little care remains is unfairly distributed, with arbitrary distinctions between (funded) health needs and (unfunded) social needs-leaving many older patients, especially those with dementia, with a wholly inadequate service.

Currently, health and social care systems are run on entirely different models. A crucial question is whether integration would mean social care becoming like healthcare: relatively comprehensive, mostly publicly provided, and funded by general taxation. The alternative-regarded by most doctors as a nightmare scenario-is that healthcare becomes like social care: patchy, mostly privately provided, and means tested.

The Lords Economic Affairs Committee clearly favours the former. It recently published Social Care Funding: Time to End a National Scandal, in which it criticised the government for repeatedly breaking its promise to tackle the social care crisis. It called for an immediate injection of $£ 8 b n$ into social care to restore provision to 2010 levels and recommended universal access to free personal care by $2025 .{ }^{4}$

Discussing our vision of integration in our small group, we came to the conclusion that our priorities were adequate funding and good communication. We could do very well without structural upheaval: we just want enough staff of all varieties to care for our patients, and for us-and our computer systems- to be able to talk to each other.

\section{Competing interests: See www.bmj.com/about-bmj/freelance-contributors.}

Provenance and peer review: Commissioned; not externally peer reviewed.

1 NHS. The NHS long term plan. 7 Jan 2019. https://www.longtermplan.nhs.uk/publication/ nhs-long-term-plan/.

2 Exley J, Abel GA, Fernandez JL, etal . Impact of the Southwark and Lambeth Integrated Care Older People's Programme on hospital utilisation and costs: controlled time series and cost-consequence analysis. BMJ Open 2019;9:e024220.

10.1136/bmjopen-2018-024220. 30833317

3 Butler P. Social care chiefs: funding crisis puts tens of thousands at risk. Guardian 2019 Jun 26. https://www.theguardian.com/society/2019/jun/26/social-care-funding-crisis-puttingtens-of-thousands-at-risk.

4 Economic Affairs Committee. Social care funding: time to end a national scandal. 4 Jun 2019. https://publications.parliament.uk/pa/d201719//dselect/ldeconaf/392/39203.htm\#_ idTextAnchor002.

Published by the BMJ Publishing Group Limited. For permission to use (where not already granted under a licence) please go to http://group.bmj.com/group/rights-licensing/ permissions 